\title{
REVIEWS
}

\section{Construction of Polypeptide-based Nano-template}

\author{
Toshihiko NiwA, ${ }^{*}$ Hidenori YoKoI, ${ }^{* * *}$ Takatoshi KInOSHITA, ${ }^{, \dagger}$ and Shuguang ZHANG** \\ ${ }^{*}$ Graduate School of Engineering, Nagoya Institute of Technology, Gokiso-cho, Showa-ku, Nagoya 466-8555, Japan \\ ${ }^{* *}$ Center for Biomedical Engineering NE47-379, Massachusetts Institute of Technology, Cambridge, MA 02139-4307, U.S.A.
}

(Received April 30, 2004; Accepted May 13, 2004; Published September 15, 2004)

\begin{abstract}
Self-organization of the ordered nano-structures composed of amphiphilic polypeptides is focused in this review. Two-dimensional arrangement of rod-like block type copolypeptides at interface has been investigated by Langmuir-Blodgett (LB) method. A diblock helical copolypeptide formed stripe pattern in the LB film based on nanophase separation. In the case of triblock helical copolypeptide, more sophisticated nano-stripe pattern was produced. The triblock copolypeptide LB film was applied as a nano-template, i.e., iron nano-particles fabricated their joined nano-wire reflecting the lane-like pattern in the LB film.

LB films of monodispersed triblock copolypeptides having leucine zipper helices at the termini (helix-loop-helix type) with designed sequence indicated not only a sophisticated nano-stripe pattern over a wide range but also a quantitative increase in the stripe interval depending on the size of loop segment. It was also shown that the mixed LB film consisting of the helix-loop-helix copolypeptide and leucine zipper helical polypeptide provided a unique phase separated structure, having a uniform rectangular-like domain. Furthermore, it was reported that the monodispersed amphiphilic $\beta$-sheet peptide formed three-dimensionally self-organized nano-fiber scaffold, yielding a transparent hydrogel containing extremely higher water content $(>99.5 \%)$.

The well-defined amphiphilic polypeptides with designed sequence and conformation emerging into various intraand inter-molecular interactions into self-assembled nano-organization will likely have great impact on the future of materials. These hierarchical ordering structures including location and arrangement of functional units on nanometer-scale will be developed for a wide range of application as a nano-template.

[DOI 10.1295/polymj.36.665]

KEY WORDS Template / Amphiphilic Polypeptide / Self-assembly / Nano-particle / LB Film /

Nano-fiber Scaffold /
\end{abstract}

The biological membranes are a dynamic molecular assembly entity, which expresses numerous astonishing functions such as selective binding and/or transformation, information transfer, energy conversion and molecular recognition through the biological interface, which is essential for a living system. While lipids construct fluid interface as two-dimensional matrix, various membrane proteins receive the physical or chemical stimulus from their environment at the interface and respond to it precisely. ${ }^{1-3}$ The molecular components of the biological membranes, lipids and membrane proteins, are amphiphilic, and so this feature induces self-assembly into a well-defined nanostructure. In this system, the specific location and/or molecular orientation of these elements are important. ${ }^{4-10}$ As a part of the membrane mimetic chemistry or supramolecular science, monolayer, bilayers and vesicles have been extensively studied using lipid-like amphiphiles. ${ }^{1-23}$ In the past, much effort has been made to produce two-dimensional ordered interfaces. ${ }^{24,25}$ For example, Oishi et al. ${ }^{22}$ reported a guest-induced molecular patterning in monolayer composed of long alkyl chains with a functional terminus. Whitesides et al. ${ }^{23}$ applied optical lithograph technique to a protein adsorbed substrate, and succeeded in forming a two-dimensional pattern. In these systems, long alkyl chains are mainly used, however, in the near future novel and advanced devices with functional molecular elements and sophisticated control of nano-structure will be appeared.

Here we report an approach to construct well-defined nano-structures using polypeptide as a molecular component. It was well known that each amino acid in the polypeptide has the character such as ionic, hydrophobic/hydrophilic and polar/non-polar depending on the individual side chains. ${ }^{26}$ Polypeptides with designed amino acid sequence form well-defined secondary structure such as $\alpha$-helices and $\beta$-sheets and flexible loop. They fix the three-dimensional location of functional side chains of amino acids to make a specific interaction spontaneously between the polypeptides, resulting in the construction of a higher ordered macro-molecular organization having functional and structural domains. ${ }^{27-36}$ In addition, polypeptide has

${ }^{\dagger}$ To whom correspondence should be addressed (E-mail: kinoshita.takatoshi@ nitech.ac.jp). 
the various characters of macro dipole moment, biodegradability and environmental adaptation, etc. Moreover, easier chemical modification of side chains of amino acids makes it possible to introduce desired functions such as electroconductivity, photoisomerization, molecular recognition, which is merit for a wide range of engineering applications. ${ }^{37}$

In this report, two-dimensional patterning using rod-like amphiphilic polymers, di- and tri-block $\alpha$ helical polypeptides, are described. ${ }^{38,39}$ To construct such a sophisticated molecular system, LangmuirBlodgett (LB) method was adopted. ${ }^{40-42}$ We discussed not only the influences of conformation, segment size and molecular weight dispersity in the components on the nano-structure of the prepared membranes but also the application as a template for nano-particle arrangement. ${ }^{43}$ Moreover, as an attempt to control a nano-structured material with three-dimensional selforganization, the ordered nano-scaffold composed of $\beta$-sheet amphiphilic peptide as a molecular component is also discussed. ${ }^{44,45}$

\section{TWO-DIMENSIONAL PATTERNING FOR TEMPLATE}

Nanoscale two-dimensional patterning on substrate using functional molecules is important for making a novel molecular device such as high-density data storage, etc. ${ }^{15-19,46-52}$ Polypeptides with well-defined secondary structure are expected to be highly functional monolayers, in addition, its two-dimensional regular pattern in the monolayer may be controllable by their molecular weight and side chain modifications, etc. Several studies concerning with the self-assembled monolayers (SAMs) on substrate using polypeptide derivatives have been reported. ${ }^{37,53-56}$ However, the two-dimensional ordering of these rod-like polymers on substrate has not been observed. On the other hand, it was shown that the adsorption of proteins onto SAM templates could yield micrometer-scale ordered layers on the substrate. ${ }^{58,59}$ We prepared monolayer composed of di- or tri-block copolypeptide at air/water interface (LB film). Controlling two-dimensional structure formation was herein studied.

\section{Amphiphilic Diblock Helical Copolypeptide, PLLys $Z_{25}-$ $P\left(M L G_{42} / L G A_{18}\right)$}

A monolayer was prepared by a diblock copolypeptide composed of hydrophilic and hydrophobic $\alpha$ helix segments. ${ }^{38,39}$ The hydrophobic segment is poly(L-lysine) derivative and the hydrophilic segment is L-glutamic acid copolymer (Figure 1).

Figure 2 shows the surface pressure-area $(\pi-A)$ isotherm obtained at $\mathrm{pH} 5$. The limiting area was estimated to be $c a .6 \mathrm{~nm}^{2} /$ molecule. The calculated limiting (a)

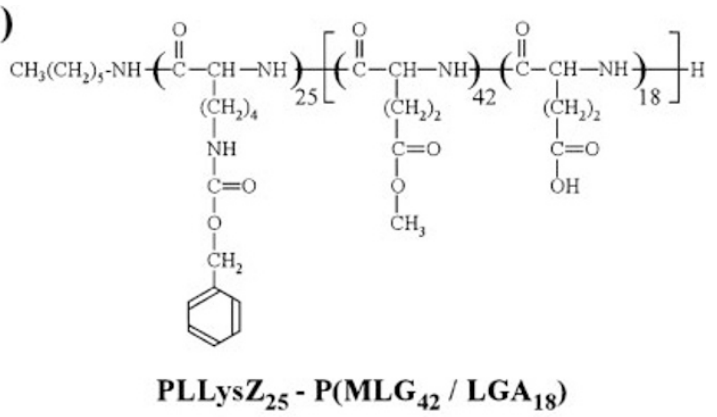

(b)

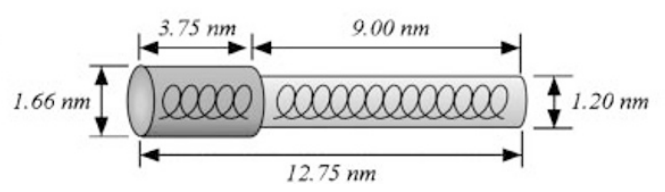

Figure 1. Chemical structure (a) and schematic illustration (b) of $\mathrm{PLLysZ}_{25}-\mathrm{P}\left(\mathrm{MLG}_{42} / \mathrm{LGA}_{18}\right)$.

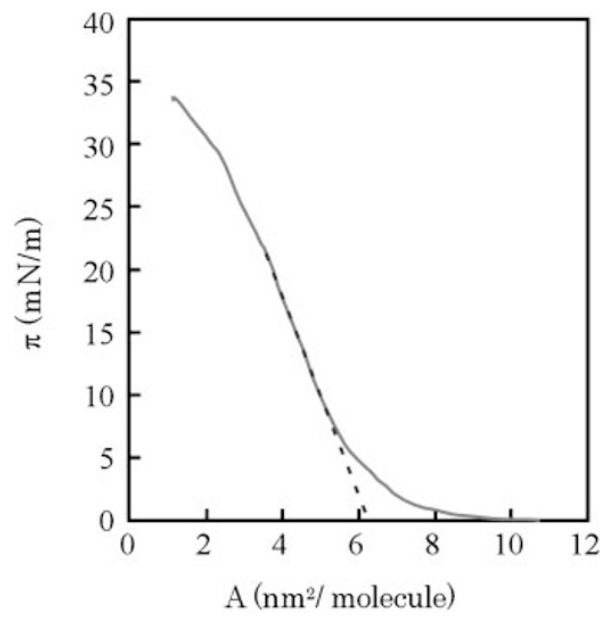

Figure 2. $\pi-A$ isotherm for a monolayer of PLLys $Z_{25}-$ $\mathrm{P}\left(\mathrm{MLG}_{42} / \mathrm{LGA}_{18}\right)$ on aqueous solution of $0.1 \mathrm{~mol} / \mathrm{L} \mathrm{KCl}$ at $\mathrm{pH} 5$.

Table I. Limiting area estimated from $\pi-A$ isotherm (Figure 2)

\begin{tabular}{|c|c|}
\hline $\begin{array}{c}\text { Observed } \\
\left(\mathrm{nm}^{2} / \text { molecule }\right)\end{array}$ & $\begin{array}{c}\text { Calculated } \\
\left(\mathrm{nm}^{2} / \text { molecule }\right)\end{array}$ \\
\hline$A_{\mathrm{pH} 5}$ & $A_{\perp}$ \\
\hline 6.26 & 2.39 \\
\hline
\end{tabular}

area when the helix is normal to the air/water interface is shown in Table I. We expected the normal orientation of the helix after compressing the membrane, however, the big difference between the calculated and observed limiting area indicated that it is impossible to obtain a standing helix monolayer using this system. So the monolayer was transferred onto a mica surface at $25 \mathrm{mN} / \mathrm{m}$ to get a LB film with a single layer. And the morphology of the LB film was observed by atomic force microscopy (AFM). Figure 3 shows the AFM image of the LB film on micrometer scale. From the depth of the cavity that was made by 


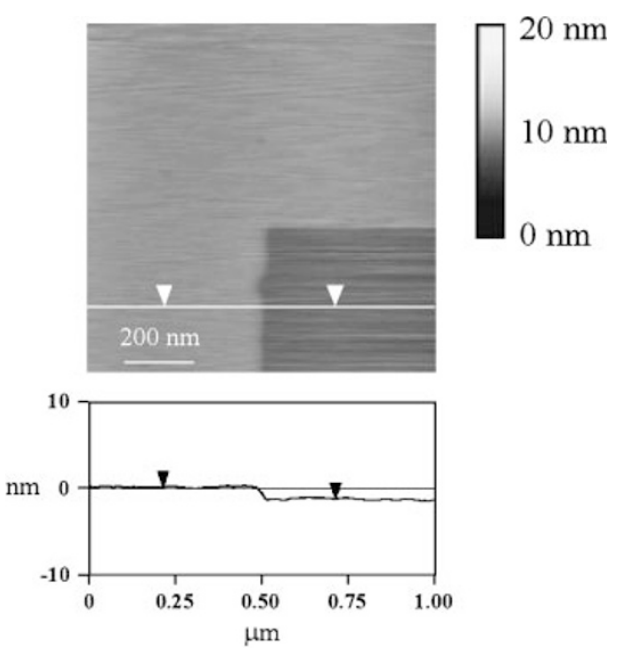

Figure 3. AFM image $(1.0 \mu \mathrm{m} \times 1.0 \mu \mathrm{m})$ of PLLysZ $_{25}-$ $\mathrm{P}\left(\mathrm{MLG}_{42} / \mathrm{LGA}_{18}\right) \mathrm{LB}$ film on mica substrate.

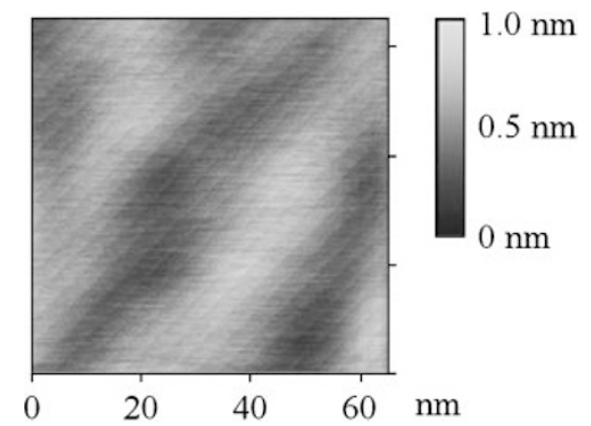

Figure 4. AFM image $(65.1 \mathrm{~nm} \times 65.1 \mathrm{~nm})$ of $\mathrm{PLLysZ}_{25}-$ $\mathrm{P}\left(\mathrm{MLG}_{42} / \mathrm{LGA}_{18}\right) \mathrm{LB}$ film on mica substrate.

scratching with a cantilever, the thickness of the membrane was estimated to be $c a$. $1.4 \mathrm{~nm}$. This value is almost consistent with the diameter of the helix, indicating that the $\alpha$-helix rods lie down on the mica surface. Figure 4 is a nanometer-scale image of the LB film. A stripe pattern composed of thick and thin layers was observed. And the difference of the thickness was ca. $0.3 \mathrm{~nm}$. This value is almost consistent with the difference between the radii of the hydrophilic and hydrophobic helix rods. This means, therefore, that the thick layer is a molecular array of the hydrophobic larger-diameter helix and the thin layer that of the hydrophilic smaller helix. The interval of the stripes was estimated to be $c a .24 \mathrm{~nm}$. This value is almost the twice the length of this polypeptide. These results suggest that this diblock copolypeptide aggregates by head to head and tail to tail, resulting in the formation of a nanophase-separated structure as is shown in Figure 5.

However, Figure 6a is the AFM image within $140 \mathrm{~nm}^{2}$, a larger area than that of Figure 3. A disordered structure was observed. That is, except for the regular stripe domain a branching pattern was also

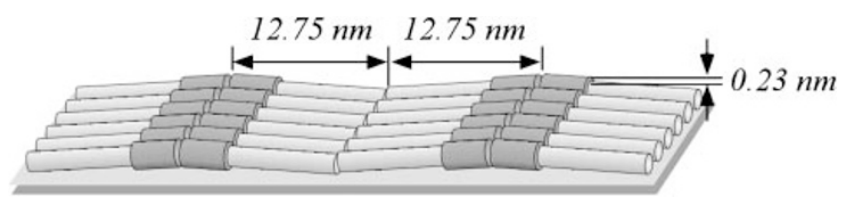

Figure 5. Schematic illustration of the nano-phase separated structure of PLLysZ ${ }_{25}-\mathrm{P}\left(\mathrm{MLG}_{42} / \mathrm{LGA}_{18}\right) \mathrm{LB}$ film on mica substrate.

(a)

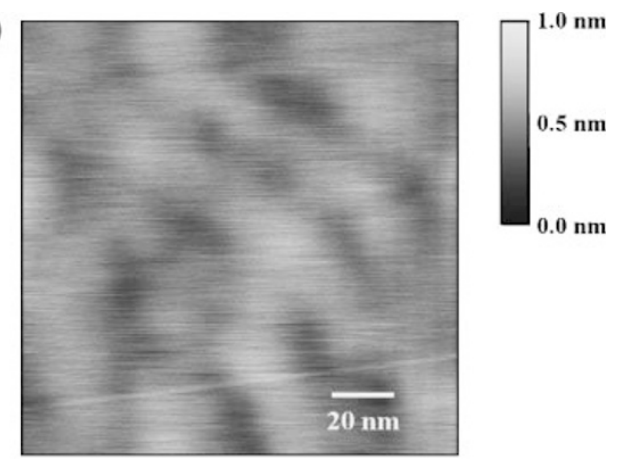

(b)

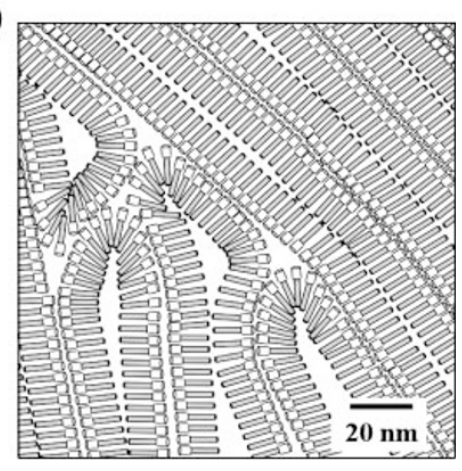

Figure 6. AFM image $(140 \mathrm{~nm} \times 140 \mathrm{~nm})$ of PLLysZ $Z_{25}$ $\mathrm{P}\left(\mathrm{MLG}_{42} / \mathrm{LGA}_{18}\right) \mathrm{LB}$ film on mica substrate (a) and its schematic illustration (b).

made. Figure $6 \mathrm{~b}$ shows a schematic illustration of the speculated monolayer structure. The authors suggested that the hydrophobic interaction and hydrogen bonding between helix rods promote the phase-separated regular pattern, however, the large difference in diameter between the two helix units is not convenient, in this case, for regular packing of the helix rods over a wide range. ${ }^{39}$

\section{Amphiphilic Triblock Helical Copolypeptide,} PLLeu $_{54}-P_{L G A_{80}-P_{L L e u} 4}$

So as a next step, the monolayer was prepared by a triblock copolypeptide, PLLeu ${ }_{54}-\mathrm{PLGA}_{80}-\mathrm{PLLeu}_{54}$, composed of hydrophobic, hydrophilic and hydrophobic helix segments (Figure 7). ${ }^{39}$ This dumbbell shape was expected to block the development of the branching pattern. ${ }^{57}$ The stable $\alpha$-helix structure of this polypeptide was confirmed by FT-IR measurements of the LB film on Au surface. In this case, the monolayer on aqueous solution at $\mathrm{pH} 4.0$ was transferred on 
(a)

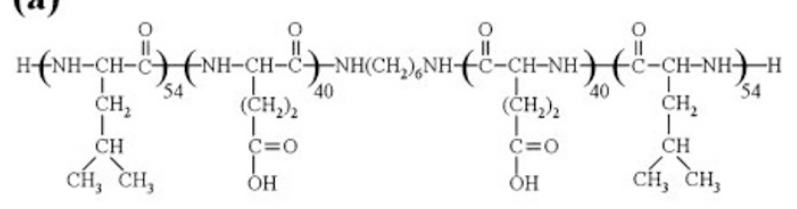

\section{PLLeu $_{54}$-PLGA 80 -PLLeu 54}

(b)

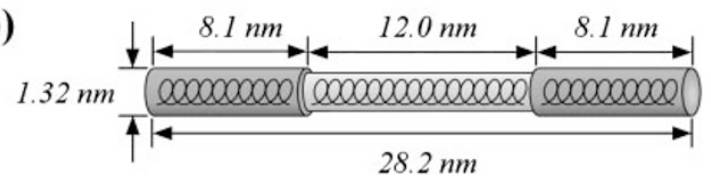

Figure 7. Chemical structure (a) and schematic illustration (b) of PLLeu ${ }_{54}-\mathrm{PLGA}_{80}-\mathrm{PLLeu}_{54}$.

an Au surface for the FT-IR measurements. So this polypeptide in the acidic condition, as schematically shown in Figure 7, is composed of a hydrophobic larger-diameter helix and a smaller-diameter hydrophilic helix. Generally, circular dichloism (CD) measurement of the polypeptide in aqueous solution at several $\mathrm{pH}$ also indicated that the carboxylic-rich hydrophilic segment of the polypeptide showed its helix-coil transition depending on $\mathrm{pH}$.

And then, the solid state monolayer (surface pressure: $17 \mathrm{mN} / \mathrm{m}$ ) on water phase at $\mathrm{pH} 4.0$ was transferred onto a mica surface to get a LB film with a single layer for AFM measurements. Figure 8a shows the AFM image of the monolayer within $140 \mathrm{~nm}^{2}$, indicating a stripe pattern composed of thick and thin layers. The interval of the stripes, in this case $c a .30 \mathrm{~nm}$, is consistent with the length of the triblock copolypeptide. So, the nanophase-separated structure of the monolayer is schematically shown in Figure 8b. As is expected, the triblock copolypeptide made more sophisticated stripe pattern with very few branching structures. In the case of LB film obtained, under constant surface pressure of $17 \mathrm{mN} / \mathrm{m}$ as same, from subphase at pH 12 (Figure 9), similar stripe pattern was observed. It may say, therefore, the thick domain corresponds to the molecular array of the hydrophilic loop composed of ionized PLGA segment and thin domain that of the hydrophobic helical PLLeu segment, respectively. The interval of stripe was smaller $(c a$. $23 \mathrm{~nm}$ ) and the difference in height of thick and thin domains was larger $(c a .0 .9 \mathrm{~nm})$ than those of LB film in acidic condition. From the AFM images of $\mathrm{pH} 4$ and 12 , it was suggested that $\mathrm{pH}$ stimuli effects on the interval of width and height of the nano-stripe in membrane.

This is a good example showing a relation between the molecular shape and character of the polypeptides and their self-organized two-dimensional structure. It is expected, therefore, that the size of this pattern (a)

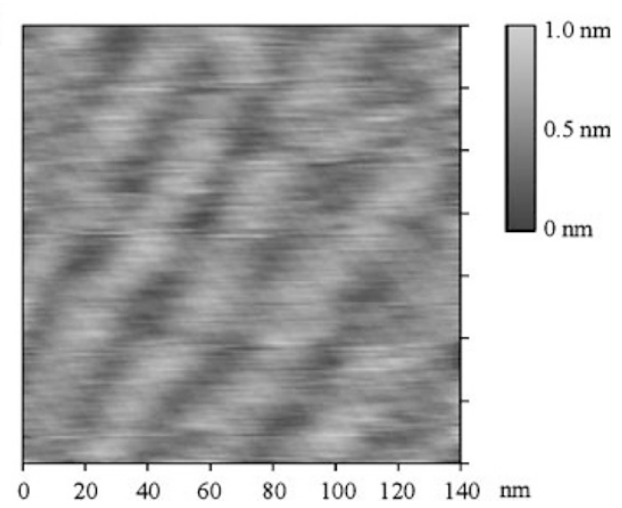

(b)

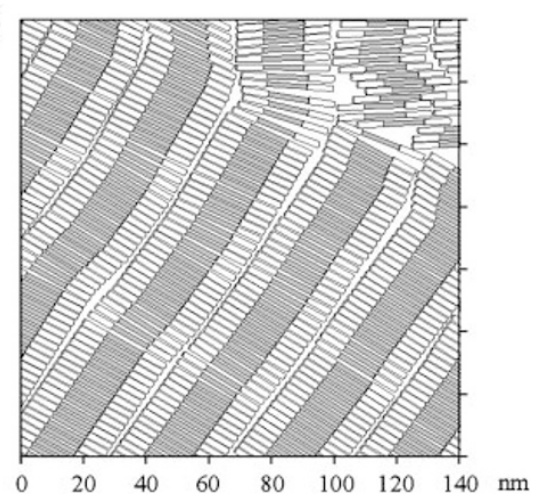

Figure 8. AFM image $(140 \mathrm{~nm} \times 140 \mathrm{~nm})$ of PLLeu $_{54}-$ $\mathrm{PLGA}_{80}-\mathrm{PLLeu}_{54} \mathrm{LB}$ film transferred onto mica substrate at $\mathrm{pH}$ 4 (a) and its schematic illustration (b).

(a)

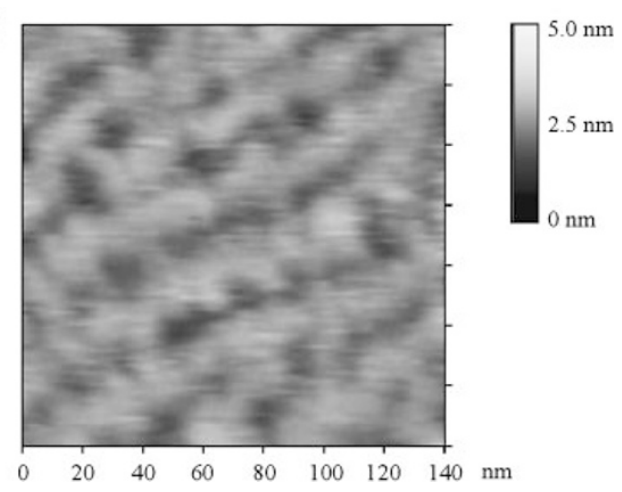

(b)

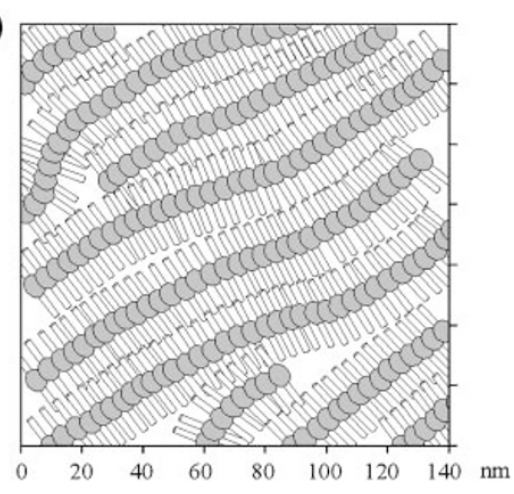

Figure 9. AFM image $(140 \mathrm{~nm} \times 140 \mathrm{~nm})$ of PLLeu $_{54}-$ PLGA $_{80}-\mathrm{PLLeu}_{54} \mathrm{LB}$ film transferred onto mica substrate at $\mathrm{pH}$ 12 (a) and its schematic illustration (b). 
can be regulated by the degree of polymerization of each helix and the functions might be controllable by the side chain structure of the $\alpha$-helix units.

Thus, these results showed the possibility of nanometer-size control of two-dimensional structure for the formation of novel functional interfaces.

\section{Nano-particles on Template}

The preparation of an array of nano-particles was made on the PLLeu ${ }_{54}-\mathrm{PLGA}_{80}-\mathrm{PLLeu}_{54}$ monolayer as a template. The nano-particle, in this case, was the iron cluster covered with the hydrophobic unsaturated alkyl chains (oleic acid/oleic amine $=1 / 1$ ). At first, the structure of a cast film of the nano-particles solution on a fleshly cleaved mica substrate was evaluated by AFM. As is shown in Figure 10, the hexagonal closest packing structure of the nano-particles with the diameter of approximately $7 \mathrm{~nm}$ was observed, indicating the uniform cluster aggregates on pure mica surface. Next, cast film of nano-particle solution on the self-assembled polypeptide LB film using triblock copolypeptide, PLLeu $_{54}-\mathrm{PLGA}_{80}-$ $\mathrm{PLLeu}_{54}$, was also prepared. The AFM image of this film (Figure 11) showed that nano-particles construct lane-like aggregates reflecting to the stripe pattern in PLLeu $_{54}-\mathrm{PLGA}_{80}-\mathrm{PLLeu}_{54}$ monolayer. This result

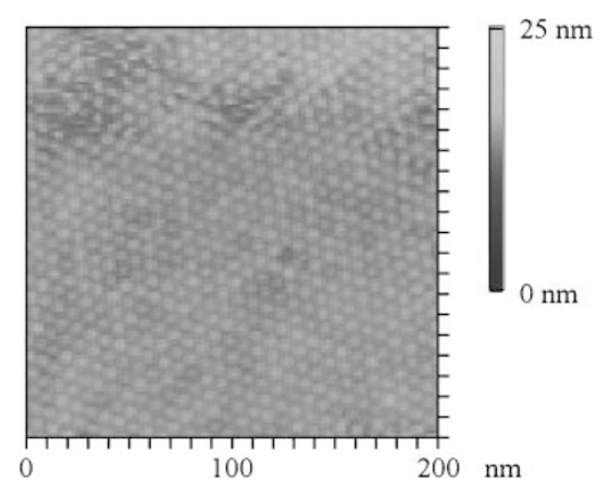

Figure 10. AFM image of Fe nano-particles on mica surface.

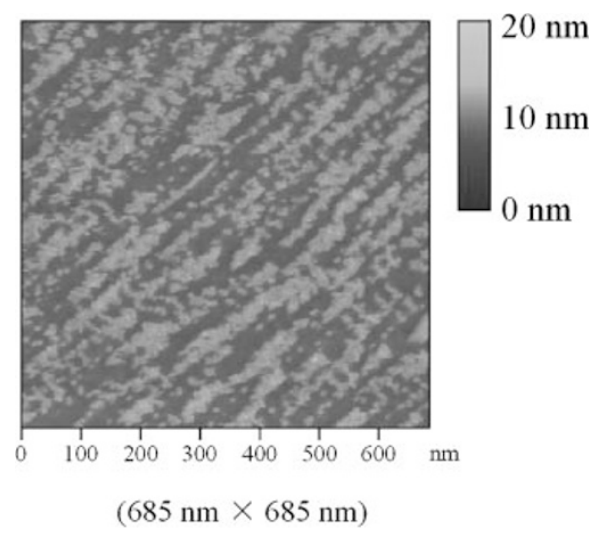

Figure 11. AFM image of nano-particles on PLLeu $4_{4-}$ PLGA $_{80}-$ PLLeu $_{54}$ LB film. suggests that the hydrophobic exterior of nano-particles selectively interacts with hydrophobic PLLeu domains of polypeptide template. Thus, molecular weight and side chains of polypeptide in the template regulate the location of functional guest-molecules such as the iron nano-particles appropriately. This may be a basic approach for the construction of electroconductive nano-wire.

\section{Triblock Type Helix-Loop-Helix Protein}

In order to create a two-dimensional nano-pattern, synthetic polypeptides are aligned at the air/water interface. Polypeptides with well-defined secondary structure are expected to form novel functional monolayers, whose two-dimensional pattern is systematically and effectively controlled by molecular weight and side chain modifications, etc. ${ }^{60}$ Moreover, the obtained nano-pattern was also found to depend strongly on the molecular shape and conformation of the polypeptide. ${ }^{38,39}$ In the case of synthetic polypeptides obtained by NCA polymerization, however, it was not easy to obtain the well-ordered nano-pattern with wide area because of their molecular weight dispersity. In order to control precisely the surface nano-structure extended over a wide area, Yokoi et al. ${ }^{61}$ have employed monodispersed artificial proteins with designed sequence and conformation as monolayer components. It is also expected that the well-defined molecular structure, shape and size of monodispersed proteins can regulate the inter-molecular interaction strictly, which would lead to create a novel nano-pattern. ${ }^{62}$

Tirrell et al. ${ }^{63}$ prepared helix-loop-helix type artificial proteins by recombinant DNA techniques. Surface activity and structural properties of the polypeptide on water were examined in the view of selforganized nano-patterning. ${ }^{61}$ The monolayer of the polypeptide shows a well-defined nano-structure over wide area. This suggests that monodispersity of the molecular element is an important factor to produce a fine nano-template.

\section{THREE-DIMENSIONAL NANO-FIBER SCAFFOLD}

The discovery and development of a class of selfassembling peptide scaffold materials for cell culture template were previously reported by Zhang's group. ${ }^{64-66}$ These short, $8-16$ residues (about 2.5$5 \mathrm{~nm}$ in length) peptides are chemically synthesized and form exceedingly stable $\beta$-sheet structures in water. They not only self-assemble to form stable nanofibers, but also form higher order nano-fiber scaffolds, namely, hydrogels with extremely high water content, $(>99.5 \%(\mathrm{w} / \mathrm{v})$ water). The gelation process is accel- 
(a)

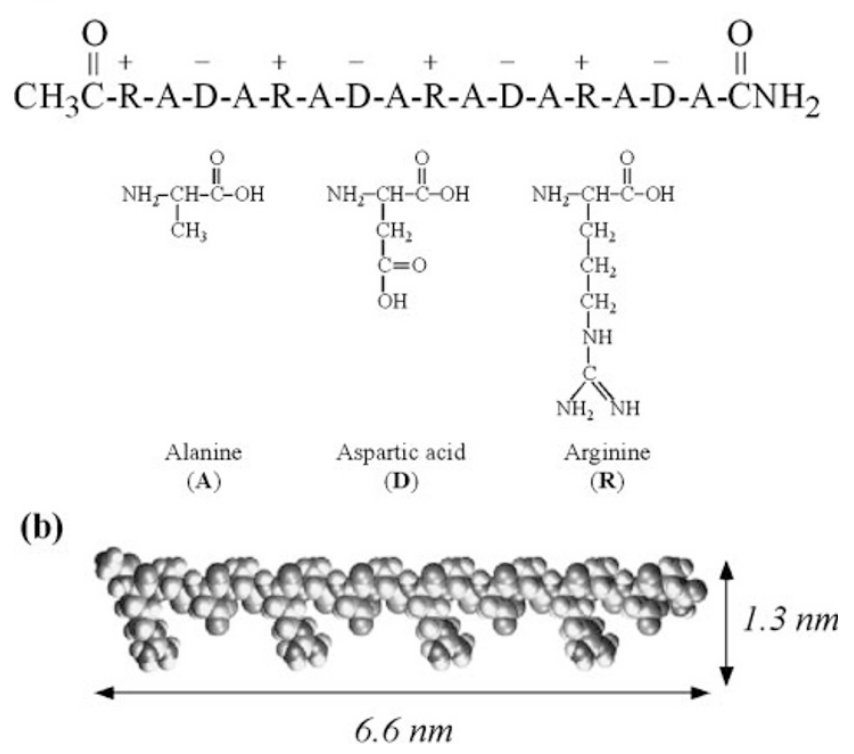

Figure 12. Amino acid sequence (a) and molecular model (b) of RADA16-I.

erated either by changing the $\mathrm{pH}$ or adding physiological concentrations of salt solutions. ${ }^{64-72}$

As a building block, monodispersed peptide having alternatively positive and negative charged amino acid residues, which form $\beta$-sheet structure with two distinct surfaces, one hydrophilic and the other hydrophobic, was chemically synthesized by Zhang's group. In hydrophilic part, arginine (R) was used as positive charged residue and aspartic acid (D) as negative charged residue, in hydrophobic part, on the other hand, alanine (A) was inserted into the sequence, and the resulted RADA repeating unit with 16 residues, RADA16-I, was employed (Figure 12a). The molecular model and its size of RADA16-I built using macromolecular simulations was shown in Figure 12b and the height and length of RADA16-I was estimated to be 1.3 and $6.6 \mathrm{~nm}$, respectively.

In order to investigate molecular structure of RADA16-I in aqueous solution, CD measurements of the RADA16-I in aqueous solution $(0.001 \mathrm{wt} \%)$ at various $\mathrm{pH}$ were carried out at $25^{\circ} \mathrm{C}$. $\mathrm{CD}$ studies of RADA16-I indicate the spectra of $\beta$-sheet formation with a minimum ellipticity at $216 \mathrm{~nm}$ and a maximum ellipticity at $195 \mathrm{~nm}$.

From AFM image observed in air with Tapping Mode, the peptide RADA16-I showed self-assembled nano-fibers (Figure 13) with lengths of a few hundred nanometers to a few microns..$^{23,24}$ The peptide-based hydrogel was prepared by adding $1 \mathrm{M}$ Tris- $\mathrm{HCl}$ buffer (pH 7.5) to RADA16-I aqueous solution ( $\mathrm{pH} 2.3$ ) and the resulted states are exhibited in Figure 14. This photograph showed the hydrogel at water content $99.9 \%$. The scaffold hydrogel is completely transpar-

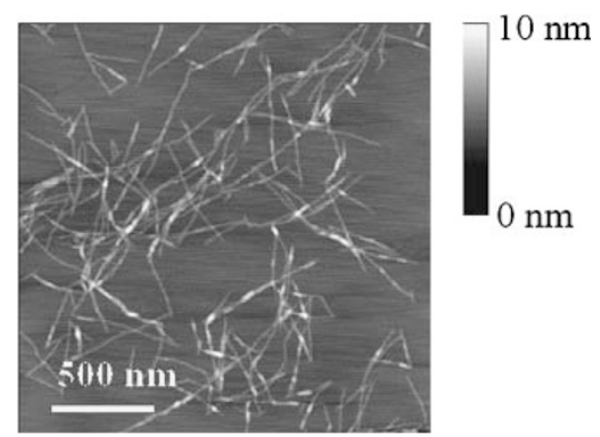

Figure 13. AFM image of RADA16-I nano-fiber scaffold $(2 \mu \mathrm{m} \times 2 \mu \mathrm{m})$.

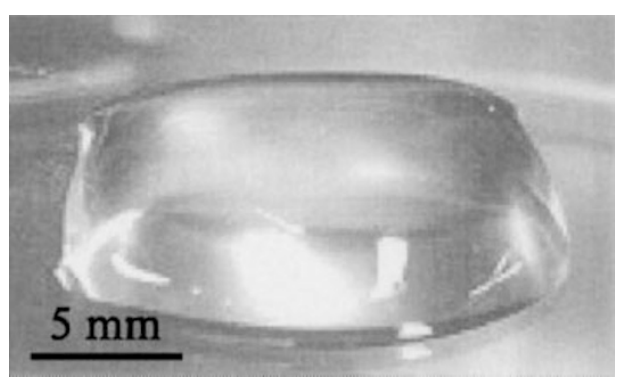

Figure 14. Photograph of RADA16-I hydrogel at condition, $0.1 \mathrm{wt} \%(\mathrm{pH} 7.5)$.

ent. These nano-fibers, if their formations can be precisely controlled, could serve as scaffold to organize nano-crystals for use in the electronic industry.

\section{CONCLUSIONS}

Molecular self-assembly is ubiquitous in nature and has emerged as a key element in the design, synthesis and fabrication of nano-devices at the molecular scale from bottom up using simple molecular building blocks. In this review, nano-structure self-assembling systems using amphiphilic peptides with various sequence and conformation were focused. It was herein revealed that amphiphilic polypeptides with designed sequence and conformation self-assembled specifically well-ordered organizations (here, stripe pattern in two-dimensional and nano-fiber scaffold in threedimensional) through hydrogen bonding, electrostatic and hydrophobic interactions according to their surround such as aqueous media or air/water interface. Monodispersity of molecular weight of the elements is thought to perform an important role to form nano-regularity over a wide area. It may say that these peptide systems will be applied for various fields such as intelligent chips, drug delivery/release systems, ${ }^{73}$ molecular recognition sensors, energy translator ${ }^{74}$ artificial nano-catalysts, ${ }^{75}$ and so on, except for the template. 
Acknowledgment. This work has been partly supported by the Grant-in-Aid from Japanese Ministry of Education, Culture, Sports, Science and Technology, Scientific Research of Priority Area (A); Dynamic Control of Strongly Correlated Soft Materials.

\section{REFERENCES}

1. J. K. Blasie, C. W. Worthington, and M. M. Dewey, J. Mol. Biol., 39, 407 (1968).

2. J. K. Blasie, Biophys. J., 12, 191 (1972).

3. R. O. Fox, Jr and F. M. Richard, Nature, 300, 25 (1972).

4. J. D. Lear, Z. R. Wasserman, and W. F. DeGrado, Science, 240, 1177 (1986).

5. B. Alberts, D. Bray, J. Lewis, M. Raff, K. Roberts, and J. D. Watson, "Molecular Biology of the Cell," 3rd ed, Garland Publishing Inc., New York \& London, 1994, chapt. 11.

6. N. Unwin, Nature, 373, 37 (1995).

7. S. K. Pollack, J. Naciri, J. Mastrangelo, C. H. Patterson, J. Torres, M. Moore, R. Shashidhar, and J. G. Kushmerick, Langmuir, 20, 1838 (2004).

8. T. Doi, T. Kinoshita, Y. Tsujita, and H. Yoshimizu, Bull. Chem. Soc. Jpn., 74, 421 (2001).

9. K. Kishihara, T. Kinoshita, T. Mori, and Y. Okahata, Chem. Lett., 1998, 951.

10. A. Toyotama, S. Kugimiya, M. Yonese, T. Kinoshita, and Y. Tsujita, Chem. Lett., 1997, 443.

11. J. P. Folkers, P. E. Laibinis, and G. M. Whitesides, Langmuir, 8, 1330 (1992).

12. K. L. Prime and G. M. Whitesides, Science, 252, 1164 (1991).

13. P. Qian, H. Nanjo, T. Yokoyama, and T. M. Suzui, Chem. Lett., 1999, 1229.

14. S. J. Stranick, A. N. Parikh, Y.-T. Tao, D. L. Allara, and P. S. Weiss, J. Phys. Chem., 98, 7636 (1994).

15. K. Tamada, M. Hara, H. Sasabe, and W. Knoll, Langmuir, 13, 1558 (1997).

16. W. Mizutani, T. Ishida, S.-I. Yamamoto, H. Tokumoto, H. Hokari, H. Azehara, and M. Fujihira, Appl. Phys. A, 66, S1257 (1998).

17. K. Nishiyama, T. T. Kie, and I. Taniguchi, Chem. Lett., 1999, 753.

18. T. Seki, H. Sekizawa, and K. Ichimura, Polym. J., 31, 1079 (1999).

19. M. Shimomura, J. Matsumoto, F. Nakamura, T. Ikeda, T. Fukasawa, K. Hasebe, T. Sawadaishi, O. Karthaus, and K. Ijiro, Polym. J., 31, 1115 (1999).

20. T. Miyashita, J. Chen, M. Yuasa, and M. Mitsuishi, Polym. J., 31, 1121 (1999).

21. W. B. Caldwell, D. J. Campbell, K. Chen, B. R. Herr, C. A. Mirkin, A. Malik, M. K. Durbin, P. Dutta, and K. G. Huang, J. Am. Chem. Soc., 117, 6071 (1995).

22. Y. Oishi, Y. Torii, T. Kato, M. Kuramori, K. Suehiro, K. Ariga, K. Taguchi, A. Kamino, H. Koyao, and T. Kunitake, Langmuir, 13, 519 (1997).

23. N. L. Abbott, J. P. Folers, and G. M. Whitesides, Science, 257, 1380 (1992).

24. B. H. Sohn, J. M. Choi, S. Il Yoo, S. H. Yun, W. C. Zin, J. C.
Jung, M. Kanehara, T. Hirata, and T. Teranishi, J. Am. Chem. Soc., 125, 6368 (2003).

25. H. Rapaport, I. Kuzmenko, M. Berfeld, K. Kjaer, J. Als-Nielsen, R. Popovitz-Biro, I. Weissbuch, M. Lahav, and L. Leiserowitz, J. Phys. Chem. B, 104, 1399 (2000).

26. S. Tsonchev, A. Troisi, G. C. Schatz, and M. A. Ratner, Nano Lett., 4, 427 (2004).

27. J. H. Collier, B. Hu, J. W. Ruberti, J. Zhang, P. Shum, D. H. Thompson, and P. B. Messersmith, J. Am. Chem. Soc., 123, 9463 (2001).

28. E. Jeoung, T. H. Galow, J. Schotter, M. Bal, A. Ursache, M. T. Tuominen, C. M. Stafford, T. P. Russell, and V. M. Rotello, Langmuir, 17, 6396 (2001).

29. K. L. Niece, J. D. Hartgerink, J. J. J. M. Donners, and S. I. Stupp, J. Am. Chem. Soc., 125, 7146 (2003).

30. R. C. Claussen, B. M. Rabatic, and S. I. Stupp, J. Am. Chem. Soc., 125, 12680 (2003).

31. D. J. Pochan, J. P. Schneider, J. Kretsinger, B. Ozbas, K. Rajagopal, and L. Haines, J. Am. Chem. Soc., 125, 11802 (2003).

32. A. Aggeli, M. Bell, L. M. Carrick, C. W. G. Fishwick, R. Harding, P. J. Mawer, S. E. Radford, A. E. Strong, and N. Boden, J. Am. Chem. Soc., 125, 9619 (2003).

33. J. P. Schneider, D. J. Pochan, B. Ozbas, K. Rajagopal, L. Pakstis, and J. Kretsinger, J. Am. Chem. Soc., 124, 15030 (2002).

34. H. J. van Manen, V. Paraschiv, J. J. Garcia-Lopez, H. Schonherr, S. Zapotoczny, G. J. Vancso, M. Crego-Calama, and D. N. Reinhoudt, Nano Lett., 4, 441 (2004).

35. E. R. Zubarev, M. U. Pralle, E. D. Sone, and S. I. Stupp, J. Am. Chem. Soc., 123, 4105 (2001).

36. C. W. G. Fishwick, A. J. Beevers, L. M. Carrick, C. D. Whitehouse, A. Aggeli, and N. Boden, Nano Lett., 3, 1475 (2003).

37. H. Yokoi, S. Hayashi, and T. Kinoshita, Prog. Polym. Sci., 28, 341 (2003).

38. H. Yokoi, T. Kinoshita, Y. Tsujita, and H. Yoshimizu, Chem. Lett., 2000, 1210.

39. H. Yokoi, S. Mizutani, and T. Kinoshita, Trans. Mater. Res. Soc. Jpn., 27, 551 (2002).

40. H. Rapaport, H. S. Kim, K. Kjaer, P. B. Howes, S. Cohen, J. Als-Nielsen, M. R. Ghadiri, L. Leiserowitz, and M. Lahav, J. Am. Chem. Soc., 121, 1186 (1999).

41. H. Rapaport, G. Möller, C. M. Knobler, T. R. Jensen, K. Kjaer, L. Leiserowitz, and D. A. Tirrell, J. Am. Chem. Soc., 124, 9342 (2002).

42. I. Kuzmenko, H. Rapaport, K. Kjaer, J. Als-Nielsen, I. Weissbuch, M. Lahav, and L. Leiserowitz, Chem. Rev., 101, 1659 (2001).

43. T. Niwa and T. Kinoshita, Electron. Parts Mater., 42, 52 (2003).

44. H. Yokoi, T. Kinoshita, and S. Zhang, submitted.

45. S. Zhang, Nat. Biotechnol., 21, 1171 (2003).

46. G. P. Lopez, H. A. Biebuyck, and G. M. Whitesides, Langmuir, 9, 1513 (1993).

47. Y. Liu, W. Zhao, X. Zheng, A. King, A. Singh, M. H. Rafailovich, J. Sokolov, K. H. Dai, E. J. Kramer, S. A. Schwarz, O. Gebizlioglu, and S. K. Sinha, Macromolecules, 27, 4000 (1994). 
48. T. L. Morkved, M. Lu, A. M. Urbas, E. E. Ehrichs, H. M. Jaeger, P. Mansky, and T. P. Russell, Science, 273, 931 (1996).

49. I. I. Potemkin, E. Y. Kramarenko, A. R. Khokhlov, R. G. Winkler, P. Reineker, P. Eibeck, J. P. Spatz, and M. Möller, Langmuir, 15, 7290 (1999).

50. S. M. Baker, K. A. Leach, C. E. Devereaux, and D. E. Gragson, Macromolecules, 33, 5432 (2000).

51. X. L. Chen and S. A. Jenekhe, Macromolecules, 33, 4610 (2000).

52. E. S. Gyorvary, A. O'Riordan, A. J. Quinn, G. Redmond, D. Pum, and U. B. Sleytr, Nano Lett., 3, 315 (2003).

53. E. T. Powers and J. W. Kelly, J. Am. Chem. Soc., 123, 775 (2001).

54. K. Fujita, N. Bunjes, K. Nakajima, M. Hara, H. Sasabe, and W. Knoll, Langmuir, 14, 6167 (1998).

55. M. Niwa, M. Morikawa, and N. Higashi, Langmuir, 15, 5088 (1999).

56. S. Kimura, Y. Miura, T. Morita, and Y. Imanishi, J. Polym. Sci., 38, 4826 (2000).

57. J. C. Love, A. R. Urbach, M. G. Prentiss, and G. M. Whitesides, J. Am. Chem. Soc., 125, 12696 (2003).

58. G. P. Lopez, H. A. Biebuyck, R. Härter, A. Kumar, and G. M. Whitesides, J. Am. Chem. Soc., 115, 10774 (1993).

59. R. G. Chapman, E. Ostuni, M. N. Liang, G. Meluleni, K. E. Gloria, L. Yan, G. Pier, H. S. Warren, and G. M. Whitesides, Langmuir, 17, 1225 (2001).

60. H. Jang, S. Kim, and K. Char, Langmuir, 19, 3094 (2003).

61. H. Yokoi, T. Kinoshita, and D. A. Tirrell, Polym. Prepr., Jpn., 51, 2401 (2002).

62. Y. Yin, Y. Lu, B. Gates, and Y. Xia, J. Am. Chem. Soc., 123,
8718 (2001).

63. W. A. Petka, J. L. Harden, K. P. McGrath, D. Wirtz, and D. A. Tirrell, Science, 281, 389 (1998).

64. T. Holmes, S. Delacalle, X. Su, A. Rich, and S. Zhang, Proc. Natl. Acad. Sci. U.S.A., 97, 6728 (2000).

65. J. Kisiday, M. Jin, B. Kurz, H. Hung, C. Semino, S. Zhang, and A. J. Grodzinsky, Proc. Natl. Acad. Sci. U.S.A., 99, 9996 (2002).

66. C. E. Semino, J. R. Merok, G. G. Crane, G. Panagiotakos, and S. Zhang, Differentiation, 71, 262 (2003).

67. S. Zhang, T. Holmes, C. Lockshin, and A. Rich, Proc. Natl. Acad. Sci. U.S.A., 90, 3334 (1993).

68. S. Zhang, T. Holmes, M. DiPersio, R. O. Hynes, X. Su, and A. Rich, Biomaterials, 16, 1385 (1995).

69. D. Marini, W. Hwang, D. A. Lauffenburger, S. Zhang, and R. Kamm, Nano Lett., 2, 295 (2002).

70. M. Caplan, P. Moore, S. Zhang, R. Kamm, and D. Lauffenburger, Biomacromolecules, 1, 627 (2000).

71. M. Caplan, E. Schwartzfarb, S. Zhang, R. Kamm, and D. Lauffenburger, Biomaterials, 23, 219 (2002).

72. M. R. Caplan, E. M. Schwartzfarb, S. Zhang, R. D. Kamm, and D. A. Lauffenburger, J. Biomater. Sci., Polym. Ed., 13, 225 (2002).

73. F. Corbellini, R. Fiammengo, P. Timmerman, M. Crego-Calama, K. Versluis, A. J. R. Heck, I. Luyten, and D. N. Reinhoudt, J. Am. Chem. Soc., 124, 6569 (2002).

74. V. Kayser, D. A. Turton, A. Aggeli, A. Beevers, G. D. Reid, and G. S. Beddard, J. Am. Chem. Soc., 126, 336 (2004).

75. F. Corbellini, L. D. Costanzo, M. Crego-Calama, S. Geremia, and D. N. Reinhoudt, J. Am. Chem. Soc., 125, 9946 (2003).

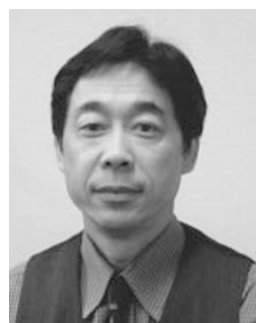

Takatoshi Kinoshita was born in Nagano prefecture in 1952. He received Bachelor and Master degrees in polymer science and engineering from Nagoya Institute of Technology, Japan in 1975 and 1977 respectively. His carrier at Nagoya Institute of Technology has included being Assistant Professor in 1991, Associate Professor in 1991, and Full Professor in 2000. He received his Doctorate degree from Tokyo Institute of Technology, Japan in 1984 on study of permeability through polypeptide membranes. During 1999-2000, he worked on artificial proteins as a visiting scientist at California Institute of Technology with Professor David A. Tirrell. He has published more than 100 papers in refereed scientific journals and 20 books and reviews, while taking out over 30 patents for his invention cooperating with several companies. His research interest covers design of Functional Interfaces and Bio-Mimetic Systems.

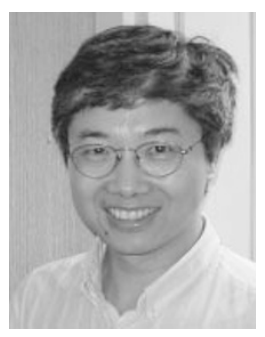

Shuguang Zhang is the Associate Director of the Center for Biomedical Engineering at the Massachusetts Institute of Technology (1998-). He received his Ph. D. in biochemistry and molecular biology from University of California at Santa Barbara (UCSB) (1988) and was a recipient of Regent Fellowship and a Graduate Mentor Fellowship at UCSB. He was past American Cancer Society Fellow at MIT (1988-1991). He discovered a self-assembling peptide system while working in molecular and structural biology with Alexander Rich at MIT. This serendipitous discovery was selected to be one of the fifteen research achievements over last quart century at MIT. He pursues actively on the various self-assembling peptide systems to develop a new class of biological materials including peptide matrix scaffold for tissue engineering, biological surface engineering for cell pattern formation, molecular switch, biological operating systems and surfactant peptide nanotubes. 


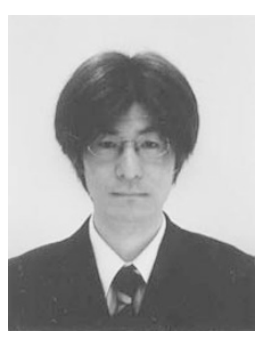

Hidenori Yokoi was born in Mie prefecture in 1977. He received his Bachelor and Master degrees in materials science and engineering from Nagoya Institute of Technology, Japan in 1999 and 2001, respectively, and received his $\mathrm{Ph}$. D. degree from Nagoya Institute of Technology, in 2004 on study of nanostructured amphiphilic peptide materials. He worked on self-assembling peptide materials as a visiting student of NITECH 21st century COE fellow at Massachusetts Institute of Technology with Professor Shuguang Zhang from September 2002 to February 2004. He joined Menicon Co., Ltd., Japan in 2004 and is currently a researcher in Central R\&D Laboratories.

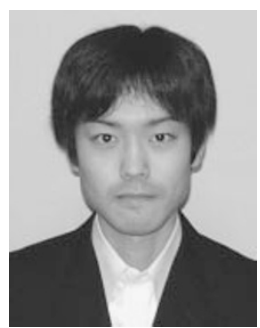

Toshihiko Niwa was born in Aichi, Japan in 1978. He received his Bachelor (2002) and Master (2004) degrees in materials science and engineering from Nagoya Institute of Technology (Japan), on study of nanometer-sized structural properties of molecular membranes through self-assembly of rod-like polypeptide elements, under supervision of Professor Takatoshi Kinoshita. He is currently a doctor course student at Nagoya Institute of Technology, and is selected as a NITECH 21st century COE student fellow. His recent work focuses in construction of functional interface based on precise control of the well-ordered nanostructures using the designed amphiphilic polypeptides derived from genetic engineering techniques. 